\title{
Identity, Intersectionality and Welfare
}

\author{
MG Majumdar \\ University of Cambridge
}

\begin{abstract}
In this paper, nuances of identity, intersectionality and welfare are explored. I begin with a historical overview of the subject followed by an evolution of the concept. I move on to different realizations of intersectionality in politics and policy-making, healthcare, education, employment and property. I end the paper with a statement, based on the workings of the paper, that true welfare is always intersectional, in nature.
\end{abstract}

Keywords: Intersectionality, Identity, Welfare

\section{Introduction}

Christina Hoff Sommers beautifully captured the central idea of this article when she said, "There is a theory behind the culture of victimhood: It's called intersectionality. This theory posits that racism, sexism, classism, ableism, etc. are interconnected, overlapping, and mutually reinforcing. Together they form a "matrix of oppression." The various axes of disadvantage in society intersect one another, mutually influencing and even modifying each other. Indeed, some widely held conceptualizations of these axes hold that race, class, and gender cannot have any meaning all by themselves. There is a certain indeterminacy of the concept of intersectionality since there is a wide range of patterns of social organization that are consistent with the core idea of intersectionality. The ways and extents to which these identities reinforce or negate the positive or negative effects of each other is up for debate.

The importance of these intersections has been reflected in its consideration in welfare policy lately, even though historically such an understanding of addressing welfare concerns has been fairly limited. For instance, Williams [1] argued that the literature on gender and the welfare state does not attend to racial/ethnic dimensions of welfare state development, while McFate et al [2] discussed how welfare policies affect race relations in their seminal book 'Poverty, inequality, and the future of social policy: Western states in the new world order', but the volume focuses on 
analyzing race and class inequality, with questions of gender mostly absent.

\section{II.Historical Overview}

Intersectionality is a concept that describes the interaction between systems of oppression. The concept primarily grew out of efforts to specify how gender and race relations shaped social and political life, mainly in the United States of America. Black feminists argued that their problems and experiences could not be described purely in terms of the problems of Black men and the problems of white women put together. There was a certain unique nature to the problems of black women that transcended this simple addition of problems associated with two disctinct identities. Black women face many problems as Black women, and their perspectives and experiences cannot be derived from looking at the experiences and position of either Black men or white women. This point was raised by feminists like Anne Julia Cooper from the 1800s when they opposed the way feminist movements were oriented at that point in time. Not that much has changed. This disparity is found in offices and society even today. As per data presented by The Lily in 2017 [4], while women in general are paid $80 \%$ of what men are paid in the USA today, black women are paid only $63 \%$ on average! This also holds true for women of colour in public officers, with only $7.1 \%$ women of colour in the US Congress in 2017 and only one in six women Governors of US states being women of colour.

Clearly, as Abby L. Ferber put it, there is no gender apart from race just as there is no race-less women. For all women, not just women of color, race shapes the experience and meaning of femininity'. Similarly, every single social position is defined by an interaction between hierarchical systems, based on hierarchies within a social identity. Speaking of gender apart from race, class, ethnicity and other divisions is inaccurate and distorting, much as it is inaccurate to speak of any of these devoid of realizing the effect of the others. As Elisabeth Spelman famously said in 1988 - "identity is not like pop-beads: People cannot discern the 'woman part' from the 'African American part' from the 'middle class part'." Some years later, Kimberlé Williams Crenshaw [3] discussed this idea of intersectionality by applying it to the specific instances of violence against women, an issue many think of as cutting across differences of race, class as well as disabilities.

Crenshaw argued in 1991 that women belonging to minority ethnic groups and marginalized races in the United States of America confront different structural barriers in trying to address the sexual violence in their lives. For example, 
non-English speaking women are often barred from women-run shelters because the English-speaking women who run these shelters are concerned they will not be able to understand their instructions and adhere to house rules and to participate in support groups! This discrimination is also seen in the housing sector. Racial segregation on the residential front means that shelters tend to be located in white communities. The position of African American women at the crossing-point of race and gender relations means that their experience of sexual violence is qualitatively and fundamentally different from the experience of either white women or African American men.

\section{II.a. Intersectionality and Simultaneity}

The term intersectionality also has historical and theoretical links to the concept of "simultaneity" which was put forward during the 1970s by the members of the Combahee River Collective, in Boston, Massachusetts. Members of this group expressed an awareness that their lives, and their manner of resistance to oppression, were profoundly influenced by race, class, gender and sexuality simultaneously. Therefore, the women of the Combahee River Collective promoted an understanding of African-American experiences that challenged analyses put forth by male-centered Black social movements; as well as those from mainstream white, middle-class, heterosexual feminists.

\section{Evolution of the Concept}

The formulation of the concept hit a road-block when some loopholes and problems were found in it. Young [5] pointed out that theoretically, the concept of intersectionality can seem to lead to an infinite regress, an infinite process of splitting of social groups, until one is left with nothing but individuals' in what is sometimes known as a matrix of domination. For example, the concept of intersectionality requires more than an acknowledgement that gender is modified by race and class since class and race are not unified categories. There are many differences among people of colour and within class groups. Social divisions based on age, disability, and national origin also play a role. Thus, various social identities and structures combine to define extremely specific social positions.

For ease of visualizing, let us consider a set of axes that can be identifies with the various identities such as gender, race, class, ethnicity, sexuality, ability, religion and nationality. This makes the analysis of social interaction and realities extremely complex. To bypass this problem, scholars of social policy who seek to use intersectionality in empirical work employ one of two strategies: Firstly, some scholars aim to consider 
intersectionality of social structures by focusing on the experiences of particular social groups. For instance, Misra and Akins [6], propose focusing on different groups of women as a way of understanding why different women have different experiences of welfare provisions. Examining specific groups of women in their interaction with the state preempts the problem of assuming a shared "women's experience." But focusing only on the particular problems of narrowly defined subgroups makes it tougher to discern how broader social structures disadvantage individuals. Moreover, this is true when we assume that each point in the plane of the axes-of-identities follows its own autonomous logic and assumes that there is absolutely nothing shared across social positions. Secondly, some scholars add the effects of various identities. Neither of these provide a comprehensive and complete idea of intersectionality. It is due to the toughness of defining social identities in isolation that the modern theory of intersectionality facing difficulties in operationalizing the concept.

\section{III.a. Identities vs. Structures}

A partial solution to this was put forward by Young [7] in the context of gender relations by distinguishing identities from social structures. He argued that "social groups defined by caste, class, race, age, ethnicity, and, of course gender name subjective identities less than axes of structural inequality. They name structural positions whose occupants are privileged or disadvantaged in relation to one another due to the adherence of actors to institutional rules and norms and the pursuit of their interests and goals within institutions". So for instance, while attributing a shared gender identity to men or women is problematic, seeing "men" or "women" as sharing a structurally defined social position is not: Thus, membership in the group called 'women' is the product of a loose configuration of various structural factors. Following Young, Htun [8] distinguished between structure and identity explicitly. He shows, for instance, how gender and sex are distinct and can be mapped from one to the other. Gender is shown to be both a category ('the multidimensional mapping of socially constructed, fluid, politically relevant identities, values, conventions, and practices conceived of as masculine and/or feminine') and a process ('behaviors, conventions, practices, and dynamics engaged in by individuals, organizations, movements, institutions, and nations'). This double conceptualization of category and process defines the structure of 'gender' and serves to recognize men and women as male and female actors with diverse and often conflicting interests that are fractured and conjoined by race, class, 
ethnicity, sexuality, age and nationalities. Gendered political research has a natural tendency to recognize that masculinities and feminities are plural, and gender as a concept can be used to understand the ways by which categories of 'feminine' and 'masculine' are mapped to individuals, communities, institutions and even practises. This decoupling of identities and structures can also facilitate the criticism of social structures by not raising problematic question of identities devoid of other associated identities. However, even with this decoupling, there still remains the need to consider the interaction of difference axes of structural inequalities.

Some scholars have proposed that all three systems (of race, gender and class) are mutually reinforcing but analytically separable, and also have some intersectional effects. Others say that one has to consider three kinds of interactions between social structures: additive, multiplicative (where multiple identities reinforce each other in a proportionate way) and intersectional (which depends on specific groups that lie at the interstices of these social structures). To illustrate this, let us say $x_{1}$ represent effects due to gender and $x_{2}$ due to race, and $x_{3}$ represents the intersectional effects of a particular gender-race configuration, then the cumulative effect can be described as $a_{1}$ $x_{1}+a_{2} x_{2}+a_{3} x_{1} \cdot x_{2}+a_{4} x_{3}$ where $\left\{a_{1}, a_{2}, a_{3}\right.$, $\left.a_{4}\right\}$ are some constants. Here the first two terms in the sum represent additive interactions, the third a multiplication interaction and the last is the intersectional interaction. The way in which allowing additive and multiplicative interactions between social structures helps is that it allows for the effects of other social structures and identities to come through. So, for instance, questions like 'Are gender, race and class entwined in a manner similar to the case seen for black women in US in other national contexts too?', where nationality starts playing a role in the analysis can be addressed using this model.

The problem of the vast number of identities and structures playing a role still remains. A good strategy may be to narrow the analysis to a particular set of intersections between social structures and focus intensively on neglected or marginalized groups placed at the interstices of several social dimensions. Comparisons with analyses that treat the more broadly defined category to which that specific group belongs as homogeneous gives us an opportunity to explore the diverse experiences of differentially located subjects.

\section{Intersectionality in Practice}


Intersectionality can be applied to a number of fields in contemporary society relating to an individual's welfare as well as collective growth, including in areas such as policy-making and politics [9-12], education [13,14], employment [15-17], healthcare [18-20], to property and wealth [21-25].

\section{IV.a. Intersectionality in Healthcare and Education}

Healthcare is a major domain where intersectionality is seen to play a significant role. Lesbian, gay, bisexual, transgender and queer (LGBTQ) individuals often face barriers and challenges to accessing health services. Access to health care is also impacted by social inequalities related to race and ethnicity, socio-economic position, and immigrant status, among others. Similarly education systems often are affected due to intersectionality. For instance, in India, class and caste and gender play a big role still in the manner in which children get education: those from poorer, backward caste/tribe communities get lower standards of education facilities, especially girl-children belonging to such families in rural India.

\section{IV.b. Intersectionality in Labour Market and Social Work}

The framework of intersectionality can also be applied to various areas where race, gender, class, ethnicity, sexuality and ability are affected by policies, practices, and laws in certain context-specific inquiries, including, for instance, analyzing the various ways in which race and gender interact with class in the labor market or interrogating the ways in which the state constitutes regulatory regimes of reproduction, and family formation. It also plays a key role in social work, for good reason, since unless social service providers take intersectionality into account, they will be of less use for the different, distinct sections of the population. For instance, given the prevalence of racially motivated police brutality, the advice of domestic violence counselors in the United States of America urging all women to report their abusers to police would be of limited use to women of color, and such counsellors should adapt their methods for such specific cases. Women with disabilities also encounter more frequent abuse both at home and even by healthcare worker and personal care attendants.

Given the pivotal role that all these social identities and structures play on the lives of people, governments often try to cater to this demand of intersectionality. Some political formations appeal to only certain identities and even go on to win power but a truly stable political regime can only stand the test of time if it facilitates the development of all its subjects, and 
that is possible only with just the right measure of welfare schemes and policies based on the idea of intersectionality. It is heartening to see some of the government initiatives these days such as crèches for children of female labourers who traditionally have been suppressed due to being women of lower classes. Now they can freely work and support their families in various countries. Other schemes like scholarships for Black and Minority Ethnic (BME) students from poorer families and the LGBTQ international initiatives of the Human Rights Watch for the welfare of LGBTQ individuals from across the globe, especially from developing countries, all behove a gradual but sure-footed advancement towards a society that respects the need for understanding intersectionality in practise as much as in conceptualization.

Welfare is a multifaceted concept and without the addressing of intersectionality therein, the concept is not truly realized. I would like to end by saying that true welfare is always intersectional in nature.

\section{Conclusion}

In this paper, the ideas of identity, intersectionality and welfare were reviewed and studied. The idea that true welfare is always intersectional in nature is proposed and supported.

\section{References:}

[1] Williams, Fiona. "Race/ethnicity, gender, and class in welfare states: A framework for comparative analysis." Social Politics: International Studies in Gender, State \& Society 2.2 (1995): 127-159.

[2] McFate, Katherine, Roger Lawson, and William Julius Wilson, eds. Poverty, inequality, and the future of social policy: Western states in the new world order. Russell Sage Foundation, 1995.

[3] Crenshaw, Kimberle. "Race, gender, and sexual harassment." S. Cal. L. Rev. 65 (1991): 1467.

[4] The Lily (News). 'The pay gap is worse for black women. Here's a look at the statistics.' July 2017. Available [online]: https://www.thelily.com/the-pay-gap-isworse-for-black-women-heres-a-look-atthe-statistics/ 
[5] Young. Iris Marion. (1994). "Gender as Seriality: Thinking about Women as a Social Collective," Signs 19(3): 713-738.

[6] Misra, Joya, and Frances Akins. "The welfare state and women: Structure, agency, and diversity." Social Politics: International Studies in Gender, State \& Society 5.3 (1998): 259-285.

[7] Young, Iris Marion. On female body experience:" Throwing like a girl" and other essays. Oxford University Press, 2005.

[8] Htun, Mala. "What it means to study gender and the state." Politics \& Gender 1.1 (2005): 157-166.

[9] Yuval-Davis, Nira. "Intersectionality and feminist politics." European journal of women's studies 13.3 (2006): 193-209.

[10] Hardy-Fanta, Carol. Intersectionality and politics: Recent research on gender, race, and political representation in the United States. Routledge, 2013.

[11] Hankivsky, Olena, and Renee Cormier. "Intersectionality and public policy: Some lessons from existing models." Political Research Quarterly 64.1 (2011): 217-229.

[12] Hankivsky, Olena, et al. "An intersectionality-based policy analysis framework: critical reflections on a methodology for advancing equity." International journal for equity in health13.1 (2014): 119.

[13] Grant, C. A., and E. Zwier. "Intersectionality and education." Encyclopedia of diversity in education 2 (2012): 1262-1270.

[14] Bhopal, Kalwant, and John Preston, eds. Intersectionality and" race" in Education. Vol. 64. Routledge, 2012.

[15] Macdonald, Cameron Lynne, and David Merrill. "Intersectionality in the emotional proletariat: a new lens on employment discrimination in service work." Service work: Critical perspectives (2009): 113-133.

[16] Warnat, Amber E. Intersectionality and employment equity in South Africa. Diss. University of Cape Town, 2012. 
[17] McBride, Anne, Gail Hebson, and Jane Holgate. "Intersectionality: are we taking enough notice in the field of work and employment relations?." Work, employment and society 29.2 (2015): 331-341.

[18] Hankivsky, Olena. "Women's health, men's health, and gender and health: Implications of intersectionality." Social science \& medicine 74.11 (2012): 1712-1720.

[19] van Mens-Verhulst, Janneke, and $H$. Lorraine Radtke. "Intersectionality and health care: support for the diversity turn in research and practice." Unpublished paper (2006).

[20] Reimer-Kirkham, Sheryl, and Sonya Sharma. "Adding religion to gender, race, and class: seeking new insights on intersectionality in health care contexts." (2011): 112-131.

[21] Brown, Tyson. "The intersection and accumulation of racial and gender inequality: Black women's wealth trajectories." The Review of Black Political Economy 39.2 (2012): 239-258
[22] Kaba, Amadu Jacky. "Explaining the Causes of the Black-White Wealth Gap in the." Sociology 1.3 (2011): 138-143.

[23] Medina, M. S. "Wealth Poverty at Social Intersections: Differential Access and Accumulation." (2017).

[24] Symington, Alison. "Intersectionality: a tool for gender and economic justice." (2004).

[25] Elu, Juliet U., and Linda Loubert. "Earnings inequality and the intersectionality of gender and ethnicity in Sub-Saharan Africa: The case of Tanzanian Manufacturing." American Economic Review 103.3 (2013): 289-92. 